\title{
Análise da interação terapeuta-cliente em sessões iniciais de atendimento
}

\author{
Analysis of therapist-patient interaction in first therapy session \\ Análisis de la interacción terapeuta-cliente en las sesiones iniciales de \\ tratamiento
}

Karina Ferraz Tozze ${ }^{1}$, Alessandra Turini Bolsoni-Silva ${ }^{2}$, Vagner Angelo Garcia ${ }^{3}$, Patricia Luiza Nunes ${ }^{4}$

[1-4] Universidade Estadual Paulista "Julio de Mesquita Filho" - Campus de Bauru/SP I Título abreviado: Interação terapêutica em sessões iniciais I Endereço para correspondência: Rua José Ferreira Marques, 10-41 apto. 507. Vila Nova Cidade Universitária. CEP: 17012-200.Bauru/SP I Email: (karina) karinatozze@ hotmail.com I (Alessandra) bolsoni@fc.unesp.br I (vagner) vagner_asp@hotmail.com I (patricia) patricia.Inunes@hotmail.com I DOI: 10.18761/pac.2015.6.1.a02 


\begin{abstract}
In the literature, the therapeutic interaction is highlighted as a key factor in the processes of change in psychotherapy sessions. The aim of this study was to identify and analyze the frequency and duration of therapists' and patients' behaviors in initial sessions. The study participants were ten students and twenty patients. The sessions were audio recorded and categorized by two observers, who used the "Verbal Vocal Therapist Behavior" Axis presented in the "Sistema Multidimensional para a Categorização de Comportamentos da Interação Terapêutica (SiMCCIT)". The results were grouped in terms of frequency and duration of the categories and correlation analyzes were carried out (Spearman's Rho test) between the categories. The "Facilitation" and "Report Request" categories were the most frequent for the therapist and the "Report" category was the most frequent for the patient. The "Report Request" (therapist) and "Report" (client) categories also presented the longest durations. There were positive correlations between the "Information"/"Establish Relations", "Information"/“Request", "Interpretation"/"Agreement" and "Approval"/"Goals" categories. The "Empathy"/“Improvement"; "Empathy"/“Request" and "Information"/“Report" categories presented negative correlations. The results seem to confirm what is expected for the first intervention sessions, in which, above all, the goal is to welcome the patient and collect data, with Facilitation and the Report Request being key strategies. We discuss implications for future studies.
\end{abstract}

Keywords: therapist-patient interaction, categorization, initial sessions, psychotherapy research process.

Resumen: La interacción terapéutica, para la terapia conductual-analítico, se identifica como un factor clave en los procesos de cambio en psicoterapia. El objetivo es identificar y analizar la frecuencia y duración de los terapeutas de conducta y clientes en las sesiones iniciales. Los participantes fueron diez y veinte personas en formación a los clientes. Las sesiones fueron grabadas en audio y categorizado por dos observadores que utilizaron el sistema de clasificación del cliente y las conductas del terapeuta (SiMCCIT). Los resultados fueron agrupados en términos de frecuencia y duración de las categorías y los análisis de correlación se realizaron (prueba Rho de Spearman) entre las categorías. Facilitación y solicitud de informes son más comunes para el terapeuta e informar al cliente. Petición de informes (terapeuta) y Presentación de Informes (cliente) son la mayor parte del tiempo. Hubo correlaciones positivas entre las categorías Informaciones / Relaciones, Información / Solicitud, Interpretación / Concordia y Aprobación / Metas. As correlaciones negativas eran Empatía / Mejora; Empatía / Solicitud de Información y / Informes. Los resultados muestran que la aplicación de Facilitación y Reportes eran la gestión principal afectada. Se discuten las implicaciones para la investigación futura.

Palabras-clave: interacción terapeuta-cliente, categorización, Las sesiones iniciales. 
A interação terapêutica tem sido foco de diversos estudos, ressaltando a importância de se identificar como ocorrem as sessões de psicoterapia, para assim descrever quais procedimentos se mostram eficazes ou não diante de determinadas queixas. A interação terapêutica vem sendo cada vez mais estudada pela Análise do Comportamento na medida em que se observam, na sua descrição, fatores de mudança clínica relevantes aos clientes (Rosenfarb, 1992).

Zamignani (2007) defende que o estudo da interação terapêutica pode ser realizado através da sistematização dos dados de sessões (verbalizações e gestos do terapeuta e do cliente) em categorias que descrevam a função desses comportamentos. Recentemente, cada vez mais pesquisadores tem estudado a interação terapêutica através da análise dos comportamentos de terapeutas e clientes em sessões mediante sistemas de categorização (Barbosa \& Tourinho, 2009; Brito, Oliveira, \& Sousa, 2003; Donadone, 2009; Garcia 2014; Garcia, 2001; Kanamota, Kanamota, \& Bolsoni-Silva, 2014; Meyer, 2009; Sadi, 2011; Silveira, BolsoniSilva, \& Meyer, 2010; Vermes, 2000; Yano, 2003; Zamignani \& Andery, 2005; Zamignani \& Meyer, 2011; Zamignani, 2007).

No estudo conduzido por Ruiz-Sancho, FrojanParga e Calero-Elvira (2013) foi investigada a influência que determinadas verbalizações do cliente exerciam nos comportamentos do terapeuta. Foram analisadas 92 sessões de atendimento, que correspondiam a 19 casos clínicos tratados por nove terapeutas comportamentais. Os resultados encontrados apontaram que o terapeuta respondia diferencialmente aos comportamentos verbais do cliente, modificando as contingências verbais quando o comportamento do cliente se aproximava ou se tornava mais distante dos objetivos terapêuticos, corroborando os achados de outro estudo (CaleroElvira et. al., 2013), em que foi identificado que o terapeuta modelava os comportamentos do cliente na medida em que se aproximavam dos objetivos da terapia.

Zamignani e Andery (2005) avaliaram a interação entre terapeutas analistas do comportamento e clientes diagnosticados com transtorno obsessivo-compulsivo e descreveram um procedimento em que foram analisadas (gravadas e transcritas) sessões de atendimento de dois terapeutas. As verbalizações foram categorizadas em descrição, explicação, aconselhamento, feedback, inferência, perguntas e outras verbalizações. A partir da análise dos dados foi possível inferir que ambos os terapeutas optaram por uma psicoterapia pautada em procedimentos menos aversivos, visto o baixo índice da categoria 'reprovação' nas sessões avaliadas. Outra característica comum a ambos os terapeutas se refere ao fato de tenderem a dar explicações com ênfase em relações resposta-consequência, de acordo com os pressupostos da análise do comportamento.

Zamignani (2007), em sua pesquisa de doutorado, desenvolveu o Sistema Multidimensional para a Categorização de Comportamentos na Interação Terapêutica (SiMCCIT) - para maior aprofundamento no tema, o leitor pode também consultar Zamignani e Meyer (2014a, 2014b) que organizaram diversos estudos próprios e de outros pesquisadores que abordam o desenvolvimento do SiMCCIT e sua aplicação em diversos contextos.

Para a construção do SiMCCIT, Zamignani (2007) fez uma revisão das categorias já existentes e descritas na literatura (Estudo I de sua tese), e constatou que as categorias existentes não eram suficientes para o estudo da interação terapêutica na terapia analítico-comportamental, e a partir desse estudo, desenvolveu um sistema de categorização (Estudo II). O sistema de categorias foi desenvolvido em três eixos: Comportamento Verbal - Eixo I; Temas - Eixo II e Respostas Motoras - Eixo III. Durante todo o processo de desenvolvimento do sistema de categorização, houve procedimentos que objetivavam legitimar o estudo, tais como treino de categorização e concordância entre os observadores e reformulações do sistema.

O Eixo I, foco deste trabalho, é subdividido em comportamento verbal vocal (falas) e comportamento verbal não vocal (gestos). Outros estudos utilizaram o sistema de categorizações desenvolvido por Zamignani (2007), tanto para sessões individuais quanto em grupo (Garcia, 2014; Rossi, 2012; Sadi, 2011; Silveira, Meyer, \& Bolsoni-Silva, 2014). A seguir apresentaremos alguns desses estudos.

No estudo conduzido por Silveira et al. (2014) foi aplicada uma versão preliminar do sistema de categorias desenvolvido por Zamignani (2007), 
adaptada para o uso em situação terapêutica de grupo, para intervenção com mães de crianças com problemas de comportamento. As categorias de terapeuta que tiveram maior frequência e duração foram: Aprovação, Recomendação, Interpretação, Informação e Solicitação de relato, sendo que Recomendação, Informação e Solicitação de reflexão foram apresentadas com frequência maior em relação ao grupo de clientes, já as demais, Aprovação, Interpretação, Solicitação de relato, Reprovação e Empatia, foram apresentadas com frequência maior às clientes individualmente. Uma vez que a intervenção promoveu mudanças comportamentais desejadas, as autoras discutem a obtenção de resultados relacionando hipóteses e contribuições para a literatura.

Fernandes (2012) utilizou o SiMCCIT (Zamignani, 2007) para investigar a ocorrência de comportamentos de uma terapeuta e sua cliente em sessões iniciais de terapia. Os resultados apontam que as categorias mais frequentes do comportamento verbal vocal da terapeuta foram de Facilitação (31,2\%), Empatia (24,1\%) e Solicitação de relato $(18,1 \%)$, e para o cliente a categoria Relato se sobressaiu em relação às demais $(61,1 \%)$.

Garcia (2014) descreveu a interação terapêutica no atendimento ao transtorno de ansiedade social utilizando o SiMCCIT (Zamignani, 2007). As sessões analisadas compreendiam treinamento de habilidades sociais e terapia comportamental. Os dados demonstram que a terapeuta procurou estimular o relato do cliente durante toda a terapia (categorias de facilitação e gestos de concordância), solicitou relato com frequência elevada, informou com maior frequência e intensidade (t) no inicio da terapia e depois menos, e durante todo o procedimento, a terapeuta procurou solicitar reflexão, interpretar, recomendar e aprovar com médias aproximadas. No Estudo III de seu trabalho, o autor realizou análises de correlação, para as categorias do terapeuta e cliente, identificando que a terapeuta apresentou uma escuta ativa na terapia, ouvindo com atenção (Solicitação de relato com Facilitação/Gestos de concordância T), sendo empático ao fornecer informações e recomendações (Empatia com Informações/Recomendações). Outra característica da intervenção é a correlação entre as categorias de Relações com Relato, Metas e Concordância que demonstra que o cliente fazia análises funcionais de acordo com seu relato e também formula metas, que configura numa importante medida de sucesso na terapia.

Em sua pesquisa de mestrado, Rossi (2012) utilizou o SiMCCIT (Zamignani, 2007) para averiguar se o eixo que se refere ao comportamento verbal vocal é capaz de identificar diferenças entre terapias bem e mal sucedidas (que atingiram ou não os objetivos propostos). Os dados discutidos por Rossi (2012) apontaram que as terapias eram consideradas bem sucedidas quando o cliente apresentava mudanças de comportamentos - adquirindo novos repertórios comportamentais e comportamentos de melhora - aqueles que quando emitidos aumentavam a probabilidade da emissão de reforçadores. Nas terapias bem sucedidas, em relação aos comportamentos do terapeuta, foi possível observar que a categoria Solicitação de relato se mostrou um pouco mais frequente; a categoria Solicitação apresentou uma porcentagem um pouco maior; e ocorreu uma correlação positiva entre Facilitação e Empatia. Nas terapias consideradas mal sucedidas, notou-se que as categorias do terapeuta Facilitação e Solicitação de reflexão variaram pouco em alguns contextos.

No estudo conduzido por Peron e Lubi (2011) foram analisadas três sessões iniciais de duas díades terapêuticas, baseando-se no SiMCCIT (Zamignani, 2007). Os resultados encontrados apontam que os comportamentos mais frequentes dos terapeutas foram o de Solicitação de relato e Facilitação e dos clientes foi a categoria de Relato. Os autores discutem que pelas sessões analisadas serem sessões iniciais de terapia, as categorias mais frequentes tanto do terapeuta quanto do cliente coincidem com o momento da intervenção, a coleta de dados e formulação do caso.

Os estudos apresentados anteriormente (Garcia, 2014; Peron \& Lubi, 2011; Rossi, 2012) descrevem os comportamentos do terapeuta e do cliente a partir de um sistema de categorização e, assim, buscam identificar padrões de comportamento do terapeuta analítico-comportamental que favorecem o sucesso da terapia e o estabelecimento de vínculo com o cliente. Observamos que cada um dos trabalhos apresentados possuíam similaridades, relacionadas ao uso do mesmo instrumento, ou seja, a análise 
da interação entre terapeuta e cliente para estudo de sessões de psicoterapia. Como demonstrado, a interação terapêutica tem possibilitado o estudo de diversas particularidades do processo terapêutico, como por exemplo, a descrição do processo terapêutico, a influência de determinada verbalização sobre o outro, análise de sessões de grupo, diferenciar entre terapias bem e mal sucedidas, a adesão ao processo terapêutico, e a análise de sessões iniciais de terapia.

Assim, o presente estudo buscou descrever quais dos comportamentos do terapeuta e cliente, previstos no SiMCCIT (Zamignani, 2007), estão presentes nas sessões iniciais e de forma mais específica, com terapeutas em processo de formação, elemento que não esteve presente nos estudos apontados. Entendendo que essas sessões são utilizadas para a coleta de dados sobre o caso e consequente formulação da intervenção a ser realizada, questiona-se se ocorrem comportamentos típicos de intervenção, tais como, recomendações, solicitação de reflexão, interpretação e informações.

Com a justificativa de auxiliar os terapeutas em formação a se prepararem para o início da prática clínica, o presente trabalho apresentou como objetivo: (a) descrever a frequência e a duração de comportamentos de terapeutas e clientes em sessões iniciais no processo da Terapia AnalíticoComportamental: (b) descrever correlações entre os comportamentos dos terapeutas e dos clientes.

\section{Método}

\section{Participantes}

Participaram do estudo dez estagiários que cursaram o Estágio Curricular de Terapia Comportamental e 20 clientes, com queixas relacionadas a habilidades sociais, práticas parentais e relacionamento conjugal. Dos estagiários, seis realizaram o estágio no ano de 2011 e outros quatro cursaram no ano de 2013. Cada estagiário atendeu a dois clientes, sendo um no início do primeiro semestre e outro no início do segundo semestre, do mesmo ano letivo. O critério de escolha para a seleção dos clientes pelos estagiários foi aleatório, exigindo apenas que estivesse dentro do rol de queixas descrito anteriormente (dificuldades de relaciona- mento interpessoal, problemas de relacionamento conjugal ou dificuldades com práticas parentais).

O projeto de pesquisa foi aprovado pelo Comitê de Ética em Pesquisa (CEP) da universidade ao qual estava vinculado, processo número $11688 / 46 / 01 / 12$. As sessões foram gravadas em áudio, sendo que clientes e estagiários (terapeutas) assinaram um Termo de Consentimento Livre e Esclarecido autorizando a utilização dos áudios para a presente pesquisa.

\section{Material}

Foram utilizadas as gravações do áudio das sessões terapêuticas, cuja duração de cada sessão variou entre 40 e 120 minutos. Também foi utilizado o Protocolo de Observação contendo categorias de comportamento do terapeuta e cliente (Zamignani, 2007), os softwares Clic (para treino das categorias), The Observer XT 7.0 (para categorização das sessões) e SPSS (para análise estatística).

O Protocolo de observação é parte anexa da elaboração do Sistema Multidimensional para a Categorização de Comportamentos na Interação Terapêutica (SiMCCIT) desenvolvido por Zamignani (2007), sendo utilizado neste trabalho apenas o Eixo - I, referentes aos comportamentos vocais do terapeuta e do cliente, em face ao recurso de gravação utilizado (áudio). Para o treinamento ao uso destas categorias, Zamignani (2007) desenvolveu um treino padronizado para observadores através de um software livre denominado Clic ${ }^{\varpi}$. Nesse programa há dois pacotes com 433 atividades. As atividades foram divididas em 15 séries para treino das categorias referentes ao terapeuta e 265 atividades divididas em nove séries para as categorias referentes ao cliente (Zamignani \& Meyer, 2011).

O software The Observer XT 7.0 (Noldus, 2005) permitiu a categorização da gravação conforme o sistema cadastrado no software. Assim, foram inseridas no programa todas as categorias desenvolvidas por Zamignani (2007).

\section{Procedimento de coleta, tratamento e análise de dados}

As sessões foram realizadas na clínica-escola de uma universidade pública no interior do estado de São Paulo. Os clientes foram selecionados pelos estagiários e pelo supervisor a partir de uma lista 
oriunda de um processo de triagem realizada previamente por psicólogos da clínica-escola.

A análise das sessões foi desenvolvida por duas alunas de iniciação científica, denominadas de Observadores, que já haviam cursado as disciplinas de formação em Terapia Comportamental. Para a análise das sessões, foi utilizado apenas o Eixo I do SiMCCIT (Zamignani, 2007), que se refere aos comportamentos vocais de terapeuta e cliente.

Para melhor manejo dos dados, os terapeutas (T) foram chamados de T1, T2, T3, T4, T5 e T6, para os atendimentos de 2011 e T7, T8, T9 e T10 para os atendimentos de 2013. No caso dos clientes, foram denominados como $\mathrm{C}$ e enumerados de 1 a 20 , sendo que a numeração seguiu a ordem dos terapeutas, ou seja, como cada terapeuta atendeu a dois clientes, os dois clientes de $\mathrm{T} 1$ foram $\mathrm{C} 1$ e $\mathrm{C} 2$, de $\mathrm{T} 2$ foram $\mathrm{C} 3$ e C4, e assim sucessivamente. Os clientes com numeração ímpar (primeiro de cada estagiário) foram atendidos no primeiro semestre e os clientes com numeração par (segundo cliente de cada estagiário) foram atendidos no segundo semestre do mesmo ano letivo.

Em relação aos comportamentos do Terapeuta foram utilizadas 11 categorias presentes no Eixo-I do SiMCCIT (Zamignani, 2007): Solicita relato, Facilitação, Empatia, Informações, Solicita reflexão, Recomendação, Interpretação, Aprovação, Reprovação e Outras verbalizações do terapeuta. Para os comportamentos do cliente, são apresentadas nove categorias presentes no Eixo-I do SiMCCIT (Zamignani, 2007): Solicitação, Relato, Melhora, Metas, Estabelece relações, Concordância, Oposição e Outras verbalizações do cliente. A pesquisa seguiu as seguintes etapas:

a) Estudo do Sistema Multidimensional para a Categorização de Comportamentos na Interação Terapêutica - SiMCCIT (Zamignani, 2007);

b) Treino sistemático de observadores para o uso do SiMCCIT através do software Clic ${ }^{\oplus}$. Esse programa foi desenvolvido para treinamento ao uso do SiMCCIT (Zamignani, 2007). Nesta etapa, os Observadores contaram com o apoio para o treinamento das categorias de um psicólogo comportamental, cursando mestrado, e com experiência no uso do SiMCCIT (Zamignani, 2007); c) Treinamento para o uso do software The Observer XT 7.0;

d) Registro das categorias no software The Observer XT 7.0: Cada categoria proposta por Zamignani (2007) foi cadastrado no software com o seu nome e com um código (letra) que possibilitou um registro rápido por ocasião da categorização das gravações. Após esse cadastro, inseriu-se o áudio da sessão e iniciou-se a análise. Assim, todas as verbalizações do terapeuta e cliente foram registradas de acordo com uma categoria do SiMCCIT, sendo que o software permitiu o registro dos dados tanto em termos de frequência quanto de duração de cada categoria. Esse procedimento foi realizado para toda a gravação, sessão a sessão;

e) Inicialmente foram avaliados 30 minutos de uma sessão escolhida aleatoriamente, para verificação do percentual de concordância entre os observadores. Esta fase foi denominada "Fase de Consenso". Para Cozby (2003), a partir de 80\% de concordância entre os observadores pode-se considerar o índice como satisfatório. Essa concordância foi avaliada através de uma ferramenta do software The Observer XT 7.0, que permitiu uma medida do Percentual de Concordância (PC) através da comparação entre o tempo de categorização de cada observador, calculado pela fórmula: $\mathrm{PC}=[$ (tempo de eventos concordantes) / (tempo concordantes+tempo discordantes)] x 100. Na fase de consenso, o software The Observer XT 7.0 apontou um percentual de concordância de $89 \%$ entre os Observadores. Uma vez atingido o percentual de concordância satisfatório, os observadores prosseguiram na análise de concordância;

f) Avaliação e ajustamento da concordância entre os observadores. Para tal, foram analisadas $20 \%$ das sessões totais, escolhidas por meio de sorteio, que totalizaram quatro sessões de atendimento. Essa nova fase foi denominada de "Fase de Concordância", sendo que neste momento, para não interferir nas categorizações, os observadores não comentaram entre si sobre dúvidas de categorização. As porcentagens de concordância para cada sessão sorteada para a fase de concordância apresentaram os seguintes índices: $80 \%, 82 \%, 84 \%$ e $87 \%$; 
g) Após a realização da concordância entre os observadores, foi iniciada a análise das sessões faltantes, divididas entre os Observadores. Esta fase foi denominada de "Fase de Categorização"; h) Identificação, através de ferramentas do software The Observer XT 7.0, da frequência e duração das categorias do Terapeuta e do Cliente em cada um dos semestres e anos letivos;

i) Para verificar se havia diferença entre as categorias comportamentais de um mesmo terapeuta no início do ano letivo e no início do segundo semestre do curso foi conduzido o Teste Wilcoxon, com utilização do SPSS, o qual verificou que as medidas não se diferenciavam. Diante desse resultado os dados foram tratados como um único grupo, denominados de sessões iniciais de atendimento;

j) Os dados de frequência e duração foram quantificados em porcentagens, como forma de uniformizar as comparações entre terapeutas e clientes, pois o tempo de cada sessão apresentou variação. Esse procedimento foi realizado para a construção das tabelas, que apresentavam a frequência e a duração dos comportamentos na díade terapêutica. Na última coluna de cada tabela, foi apresentada a porcentagem geral entre as categorias de terapeuta e de cliente;

k) Realização do teste de correlação de Spearman's rho, para correlacionar as categorias de comportamentos dos terapeutas e dos clientes.

\section{Resultados}

Os resultados estão organizados em termos de frequência relativa dos comportamentos dos terapeutas e clientes (Tabela 1), duração relativa de cada categoria comportamental dos terapeutas e clientes (Tabela 2), correlações da frequência entre os comportamentos do terapeuta e cliente (Tabela 3) e da duração (Tabela 4).

Como observado na Tabela 1, o estudo identificou que em sessões iniciais de terapia, os comportamentos de Facilitação e Solicitação de relato foram os mais frequentes para o grupo de Terapeutas e os comportamentos de Relato e Concordância, para o conjunto de Clientes. Contudo, outros comportamentos também foram apresentados.
Para os terapeutas, os comportamentos de Empatia, Informações, Interpretação e Solicita Reflexão, apesar de menor expressividade, estiveram presentes durante as sessões. Em relação aos comportamentos de Recomendação, Aprovação e Reprovação, observa-se pouca expressividade de frequência/duração. Para os clientes, os comportamentos de Solicitação, Outras vocal (categoria residual) e Estabelece de relações também foram de menor destaque. As categorias de Metas, Oposição e Melhora foram muito pouco frequentes.

Em relação ao tempo de ocorrência de cada comportamento, presente na Tabela 2, os resultados apontaram que, para os Terapeutas, os comportamentos de Solicitação de relato e de Informações foram os de maior duração. Embora, houvesse a ocorrência de outros comportamentos, entre eles, Empatia, Interpretação, Outras vocal, Recomendação, Solicita reflexão e Aprovação. Para os Clientes, foram os comportamentos de Relato e Estabelecimento de relações que tiveram maior duração. Mas também se pode contabilizar a duração, embora menor, de outros comportamentos nas sessões, entre eles: Outras vocal, Solicitação, Metas, Concordância, Oposição e Melhora.

Quanto às análises de correlação entre as frequências dos comportamentos do Terapeuta e do Cliente, apresentados na Tabela 3, foram identificados 12 correlações, e destas, a metade foi com categorias residuais (Outras vocal, Registro insuficiente) que não possibilitam inferir relações significativas para análise. Assim, houve correlações positivas entre as categorias de Informações/Relações; Informações/Solicitação e Interpretação/Concordância; e correlações negativas entre Empatia/Melhora; Empatia/Solicitação e Informações/Relato.

Para os dados de duração (Tabela 4), o Teste Spearman's rho, apontou apenas uma correlação positiva com variáveis significativas, entre as categorias de Aprovação (Terapeuta) e Metas (Cliente). Houveram outras cinco correlações com nível de significância - Informações/ Outras vocal cliente, Outras vocal terapeuta/Outras vocal cliente, Outras vocal terapeuta/Solicitação, Registro insuficiente/ Metas - mas com categorias residuais que não permitem uma análise significativa do processo terapêutico. 
Tabela 1: Frequência relativa (em porcentagem) das categorias do terapeuta e cliente nas sessões iniciais

\begin{tabular}{|c|c|c|c|c|c|c|c|c|c|c|c|c|c|c|c|c|c|c|c|c|c|c|}
\hline $\begin{array}{l}\text { Cate } \\
\text { (Zan }\end{array}$ & $\begin{array}{l}\text { rias } \\
\text { nani, 2007) }\end{array}$ & $\begin{array}{l}\bar{\Phi} \\
\stackrel{\stackrel{c}{\sigma}}{\bar{U}}\end{array}$ & 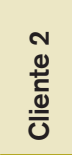 & 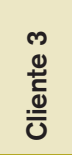 & 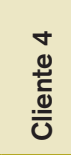 & 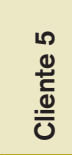 & 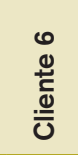 & 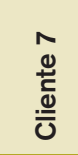 & 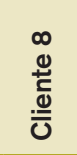 & 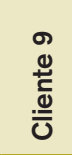 & 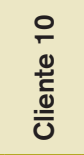 & $\begin{array}{l}\bar{\tau} \\
\stackrel{ \pm}{ \pm} \\
\frac{\bar{\sigma}}{U}\end{array}$ & 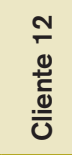 & 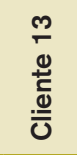 & $\begin{array}{l}\stackrel{ \pm}{ \pm} \\
\stackrel{ \pm}{ \pm} \\
\frac{\bar{\sigma}}{U}\end{array}$ & 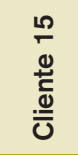 & 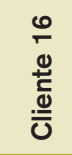 & 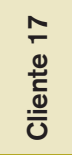 & 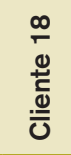 & 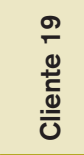 & 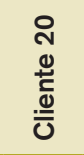 & 휴 \\
\hline & Facilitação & 67,2 & 51,4 & 42,6 & 16,9 & 59,6 & 84,8 & 38,3 & 38,8 & 59,2 & 59,9 & 50,8 & 55,6 & 47,1 & 55,1 & 78,7 & 61,5 & 42,1 & 40,6 & 14,3 & 48,4 & 55,8 \\
\hline & Solicita relato & 19,3 & 29,3 & 41,2 & 68,3 & 29,7 & 8,9 & 41,2 & 46,9 & 30,0 & 18,4 & 27,2 & 26,7 & 31,6 & 20,5 & 16,9 & 19,0 & 45,8 & 41,8 & 71,4 & 38,0 & 28,8 \\
\hline & Empatia & 1,1 & 1,6 & 3,9 & 4,2 & 2,7 & 2,8 & 3,2 & 1,9 & 2,9 & 7,8 & 9,3 & 14,8 & 6,3 & 10,2 & 2,9 & 10,8 & 7,5 & 8,8 & 14,3 & 8,1 & 5,2 \\
\hline & Informações & 7,6 & 9,0 & 2,1 & 2,1 & 3,3 & 1,4 & 7,2 & 5,6 & 3,6 & 5,1 & 2,3 & 0,7 & 5,7 & 4,0 & 0,5 & 2,6 & 1,9 & 1,8 & 0,0 & 1,8 & 3,8 \\
\hline & Outras vocal T. & 3,0 & 7,4 & 4,2 & 1,4 & 3,5 & 0,7 & 4,0 & 1,3 & 1,8 & 1,4 & 0,9 & 0,0 & 3,4 & 4,5 & 0,0 & 1,7 & 0,0 & 2,4 & 0,0 & 0,0 & 2,4 \\
\hline \& & Interpretação & 0,8 & 1,0 & 3,5 & 4,2 & 0,9 & 1,2 & 1,8 & 1,9 & 0,7 & 2,4 & 6,9 & 1,5 & 0,0 & 2,8 & 0,0 & 3,5 & 0,9 & 0,0 & 0,0 & 0,0 & 2,0 \\
\hline r & Solicita reflexão & 1,1 & 0,3 & 2,1 & 2,8 & 0,3 & 0,0 & 3,6 & 3,1 & 0,7 & 0,7 & 0,9 & 0,0 & 2,3 & 1,1 & 1,0 & 0,0 & 1,9 & 4,7 & 0,0 & 3,2 & 1,2 \\
\hline & Recomendação & 0,0 & 0,0 & 0,0 & 0,0 & 0,0 & 0,0 & 0,0 & 0,0 & 0,0 & 4,4 & 0,4 & 0,0 & 3,4 & 1,1 & 0,0 & 0,9 & 0,0 & 0,0 & 0,0 & 0,0 & 0,5 \\
\hline & Aprovação & 0,0 & 0,0 & 0,4 & 0,0 & 0,0 & 0,2 & 0,4 & 0,6 & 0,0 & 0,0 & 1,4 & 0,7 & 0,0 & 0,6 & 0,0 & 0,0 & 0,0 & 0,0 & 0,0 & 0,5 & 0,3 \\
\hline & T. reg. ir & 0 & 0,0 & 0,0 & 0,0 & 0,0 & 0,0 & 0,4 & 0,0 & 1,1 & 0,0 & 0,0 & 0,0 & 0,0 & 0,0 & 0,0 & 0,0 & 0,0 & 0,0 & 0,0 & 0,0 & 0,1 \\
\hline & Reprovação & 0,0 & 0,0 & 0,0 & 0,0 & 0,0 & 0,0 & 0,0 & 0,0 & 0,0 & 0,0 & 0,0 & 0,0 & 0,0 & 0,0 & 0,0 & 0,0 & 0,0 & 0,0 & 0,0 & 0,0 & 0,0 \\
\hline & Relato & 59,7 & 62,8 & 81,5 & 91,0 & 79,7 & 96,7 & 74,0 & 81,3 & 89,8 & 81,1 & 85,3 & 95,1 & 90,0 & 77,4 & 84,3 & 71,6 & 96,3 & 91,0 & 100,0 & 97,9 & 80,8 \\
\hline & Concordância & 3,5 & 15,5 & 6,9 & 1,6 & 5,5 & 1,6 & 8,3 & 6,3 & 2,0 & 6,6 & 8,5 & 4,9 & 0,0 & 13,2 & 11,8 & 12,7 & 3,7 & 2,2 & 0,0 & 1,0 & 6,3 \\
\hline & Solicitação & 20,4 & 6,1 & 4,0 & 4,1 & 2,9 & 1,6 & 10,1 & 7,3 & 4,1 & 7,5 & 3,6 & 0,0 & 6,3 & 1,9 & 3,9 & 7,8 & 0,0 & 3,4 & 0,0 & 0,0 & 5,9 \\
\hline & Outras vocal C. & 11,9 & 7,4 & 5,2 & 0,8 & 7,1 & 0,0 & 5,3 & 1,0 & 3,1 & 0,9 & 1,3 & 0,0 & 3,8 & 5,7 & 0,0 & 2,9 & 0,0 & 3,4 & 0,0 & 0,0 & 4,2 \\
\hline & Est. relações & 1,0 & 7,4 & 1,7 & 0,0 & 4,8 & 0,0 & 0,6 & 1,0 & 0,0 & 2,8 & 0,0 & 0,0 & 0,0 & 0,0 & 0,0 & 2,9 & 0,0 & 0,0 & 0,0 & 0,0 & 1,7 \\
\hline & Metas & 0,0 & 0,0 & 0,6 & 0,0 & 0,0 & 0,0 & 1,8 & 0,0 & 1,0 & 0,0 & 0,9 & 0,0 & 0,0 & 1,9 & 0,0 & 2,0 & 0,0 & 0,0 & 0,0 & 1,0 & 0,5 \\
\hline & Oposição & 3,5 & 0,0 & 0,0 & 0,8 & 0,0 & 0,0 & 0,0 & 0,0 & 0,0 & 0,9 & 0,4 & 0,0 & 0,0 & 0,0 & 0,0 & 0,0 & 0,0 & 0,0 & 0,0 & 0,0 & 0,4 \\
\hline & Melhora & 0,0 & 0,7 & 0,0 & 0,0 & 0,0 & 0,0 & 0,0 & 3,1 & 0,0 & 0,0 & 0,0 & 0,0 & 0,0 & 0,0 & 0,0 & 0,0 & 0,0 & 0,0 & 0,0 & 0,0 & 0,2 \\
\hline & C. reg. Insufic. & 0,0 & 0,0 & 0,0 & 1,6 & 0,0 & 0,0 & 0,0 & 0,0 & 0,0 & 0,0 & 0,0 & 0,0 & 0,0 & 0,0 & 0,0 & 0,0 & 0,0 & 0,0 & 0,0 & 0,0 & 0,1 \\
\hline
\end{tabular}

Tabela 2: Duração relativa (em porcentagem) das categorias do terapeuta e cliente nas sessões iniciais

Categorias

(Zamignani, 2007)
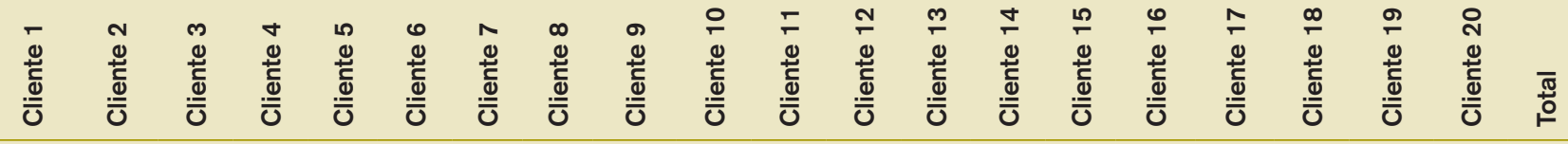

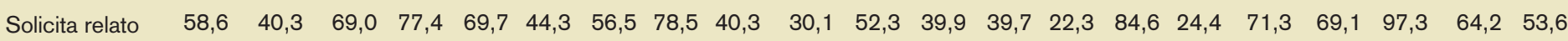

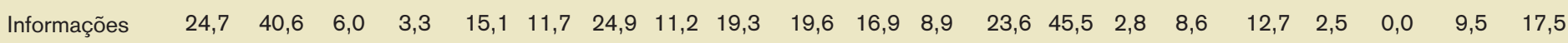

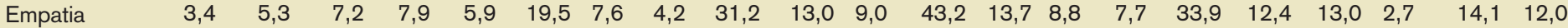

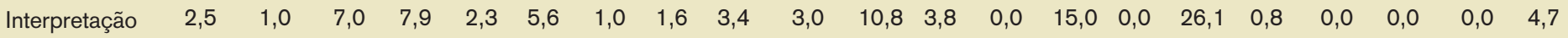

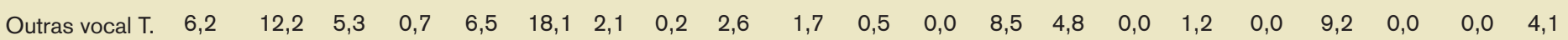

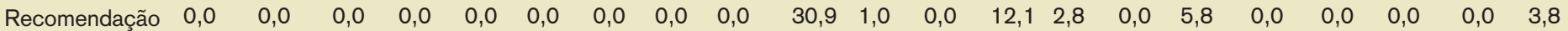

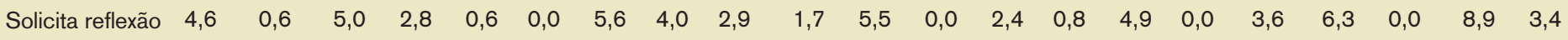

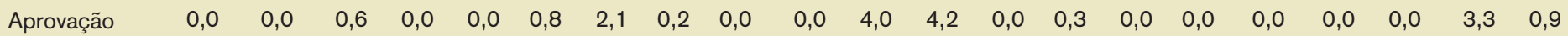

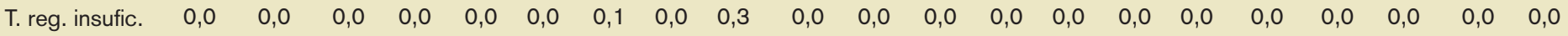

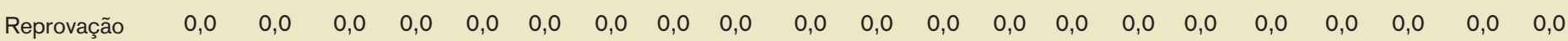


Tabela 2: continuação

\begin{tabular}{|c|c|c|c|c|c|c|c|c|c|c|c|c|c|c|c|c|c|c|c|c|c|c|}
\hline \multicolumn{2}{|c|}{$\begin{array}{l}\text { Categorias } \\
\text { (Zamignani, 2007) }\end{array}$} & 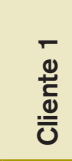 & 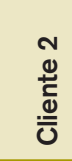 & 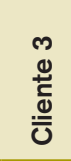 & 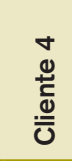 & 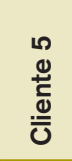 & 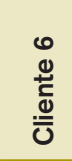 & 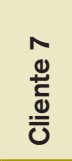 & $\begin{array}{l}\infty \\
\Phi \\
\stackrel{\Delta}{ \pm} \\
\stackrel{\Phi}{U}\end{array}$ & 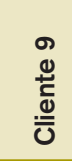 & 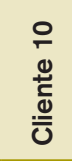 & 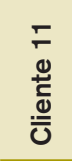 & 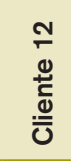 & 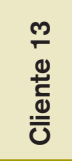 & 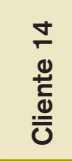 & 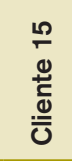 & 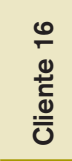 & 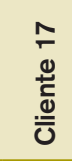 & $\begin{array}{l}\frac{\infty}{\Phi} \\
\frac{ \pm}{\sigma} \\
\frac{\Phi}{\sigma}\end{array}$ & $\begin{array}{l}\frac{9}{\sigma} \\
\frac{\pi}{0} \\
\frac{\sigma}{0} \\
0\end{array}$ & 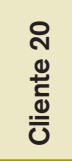 & $\begin{array}{l}\overline{\frac{\pi}{0}} \\
\text { (2) }\end{array}$ \\
\hline \multirow{9}{*}{$\stackrel{\stackrel{\Perp}{\tau}}{\underline{\underline{\omega}}}$} & ato & & 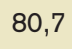 & 1 & 5 & 3,7 & 99,7 & 1,2 & 96,4 & c & , 1 & 3,7 &, 4 & 4,9 &, 5 & 9,0 & 3,2 &, 6 & 7,6 & 0,0 & 7,9 & 6,7 \\
\hline & 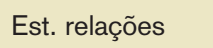 & 0,4 & . & 0,4 & 0,0 & 4,0 & 0,0 & 0,8 & 0,2 & 0,0 & 2,2 & 0,0 & 0,0 & 0,0 & 0,0 & 0 & 2,1 & 0,0 & 0,0 & (0 & 0,0 & 0 \\
\hline & Outr & 2,3 & 3 & 1,2 & 0, & 14 & 0, & 0,2 & 0,1 & 0 , & 0,0 & 0,3 & 0,0 & 2 , & 1,0 & 0,0 & 0. & 0, & 1,1 & $0, C$ & 0 & 0,7 \\
\hline & Solicitação & 1,3 & 1,5 & 0,5 & 0,2 & 0,3 & 0,2 & 1,2 & 0,7 & 0, & 2,0 & 0,3 & 0,0 & 3,0 & 0,0 & 0,4 & 0,6 & 0,0 & 0,7 & 0,0 & 0,0 & 0,6 \\
\hline & Metas & 0,0 & 0 & טיד & 0,0 & 0,0 & 0,0 & 0,2 & 0,0 & $c$ & 0,0 & 0,4 & 0,0 & 0,0 & 1,0 & 0,0 & 0,4 & 0, & 0 , & 0,0 & 2,0 & 0 \\
\hline & Conc & 0,0 & 2, & o, & 0,0 & 0,6 & 0 & 0,4 & 0,3 & 0, & 0 , & 0,3 & 0,6 & 0,0 & 0,5 & 0,6 & 0,7 & $6,-7$ & 0,0 & 6,0 & 0,1 & 0 \\
\hline & Oposição & 8 & 0,0 & 0,0 & 0,0 & 0,0 & 0,0 & 0,0 & 0,0 & $0, C$ & 02 & 0,1 & 0,0 & 0,0 & 0,0 & 0,0 & 0,0 & 0,0 & 0,0 & 0,0 & 0,0 & 0,1 \\
\hline & Mielnora & & 0,0 & , & 0,0 & 0,0 & 0,0 & 0,0 & 2,3 & 0 & U, & 0, & 0,0 & 0,0 & 0,0 & 0,0 & 0,0 & 0, & 0, & 0,0 & 0,0 & 0,1 \\
\hline & C. reg. Insufic. & , & , & 0,0 & 0,2 & 0,0 & 0,0 & 0,0 & 0,0 & 0,0 & 0,0 & 0,0 & 0,0 & 0,0 & 0,0 & 0,0 & 0,0 & 0,0 & 0,0 & 0,0 & 0,0 & 0,0 \\
\hline
\end{tabular}

* A categoria Facilitação (FAC) não apresenta duração, pois se trata de categoria do tipo evento, em que se contabiliza apenas a sua ocorrência.

Tabela 3: Análises de correlação (Teste Sperman's rho), referentes aos dados de frequência entre categorias do Terapeuta e Cliente

\begin{tabular}{|c|c|c|c|c|c|c|c|c|c|c|}
\hline $\begin{array}{l}\text { Categorias do } \\
\text { Terapeuta }\end{array}$ & Ctegorias do Cliente & 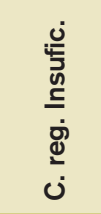 & $\begin{array}{l}\frac{\pi}{U} \\
\frac{\pi}{\mathbb{T}} \\
\frac{0}{0} \\
0 \\
0 \\
0 \\
0\end{array}$ & 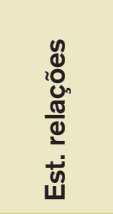 & 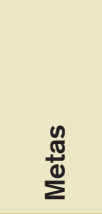 & $\begin{array}{l}\frac{\pi}{0} \\
\frac{0}{0} \\
\frac{0}{\Sigma}\end{array}$ & 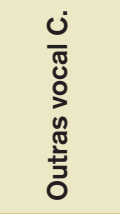 & $\frac{\frac{0}{\pi}}{\frac{\pi}{00}}$ & 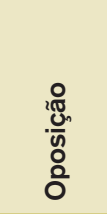 & 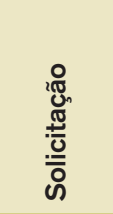 \\
\hline Aprovação & $\begin{array}{l}\text { Coef.Correlação } \\
\text { Significância }\end{array}$ & $\begin{array}{l}-0,180 \\
0,448\end{array}$ & $\begin{array}{l}0,224 \\
0,342\end{array}$ & $\begin{array}{l}-0,200 \\
0,399\end{array}$ & $\begin{array}{l}0,387 \\
0,091\end{array}$ & $\begin{array}{l}0,116 \\
0,627\end{array}$ & $\begin{array}{l}-0,123 \\
0,606\end{array}$ & $\begin{array}{l}0,090 \\
0,706\end{array}$ & $\begin{array}{l}-0,110 \\
0,644\end{array}$ & $\begin{array}{l}-0,254 \\
0,279\end{array}$ \\
\hline Empatia & $\begin{array}{l}\text { Coef. Correlação } \\
\text { Significância }\end{array}$ & $\begin{array}{l}-0,020 \\
0,934\end{array}$ & $\begin{array}{l}-0,063 \\
0,791\end{array}$ & $\begin{array}{l}-0,425 \\
0,062\end{array}$ & $\begin{array}{l}0,312 \\
0,180\end{array}$ & $\begin{array}{l}-, 461^{\star} \\
0,041\end{array}$ & $\begin{array}{l}-0,410 \\
0,072\end{array}$ & $\begin{array}{l}0,415 \\
0,069\end{array}$ & $\begin{array}{l}-0,088 \\
0,711\end{array}$ & $\begin{array}{l}-, 466^{*} \\
0,049\end{array}$ \\
\hline Facilitação & $\begin{array}{l}\text { Coef. Correlação } \\
\text { Significância }\end{array}$ & $\begin{array}{l}-0,338 \\
0,145\end{array}$ & $\begin{array}{l}0,275 \\
0,241\end{array}$ & $\begin{array}{l}0,206 \\
0,383\end{array}$ & $\begin{array}{l}0,019 \\
0,938\end{array}$ & $\begin{array}{l}-0,183 \\
0,439\end{array}$ & $\begin{array}{l}0,059 \\
0,803\end{array}$ & $\begin{array}{l}-0,317 \\
0,174\end{array}$ & $\begin{array}{l}0,127 \\
0,594\end{array}$ & $\begin{array}{l}0,112 \\
0,637\end{array}$ \\
\hline Informações & $\begin{array}{l}\text { Coef. Correlação } \\
\text { Significância }\end{array}$ & $\begin{array}{l}-0,080 \\
0,739\end{array}$ & $\begin{array}{l}0,335 \\
0,149\end{array}$ & $\begin{array}{l}0,581^{\star *} \\
0,007\end{array}$ & $\begin{array}{l}0,158 \\
0,507\end{array}$ & $\begin{array}{l}0,428 \\
0,060\end{array}$ & $\begin{array}{l}0,783^{\star *} \\
0,000\end{array}$ & $\begin{array}{l}-, 777^{\star *} \\
0,000\end{array}$ & $\begin{array}{l}0,262 \\
0,264\end{array}$ & $\begin{array}{l}0,765^{\star *} \\
0,000\end{array}$ \\
\hline Interpretação & $\begin{array}{l}\text { Coef. Correlação } \\
\text { Significância }\end{array}$ & $\begin{array}{l}0,341 \\
0,141\end{array}$ & $\begin{array}{l}0,522^{*} \\
0,018\end{array}$ & $\begin{array}{l}0,306 \\
0,189\end{array}$ & $\begin{array}{l}0,348 \\
0,133\end{array}$ & $\begin{array}{l}0,093 \\
0,696\end{array}$ & $\begin{array}{l}0,133 \\
0,575\end{array}$ & $\begin{array}{l}-0,359 \\
0,120\end{array}$ & $\begin{array}{l}0,365 \\
0,113\end{array}$ & $\begin{array}{l}0,269 \\
0.251\end{array}$ \\
\hline Outras vocal T. & $\begin{array}{l}\text { Coef. Correlação } \\
\text { Significância }\end{array}$ & $\begin{array}{l}-0,040 \\
0,867\end{array}$ & $\begin{array}{l}0,390 \\
0,089\end{array}$ & $\begin{array}{l}0,537^{\star} \\
0,015\end{array}$ & $\begin{array}{l}0,262 \\
0,264\end{array}$ & $\begin{array}{l}0,186 \\
0,432\end{array}$ & $\begin{array}{l}0,097^{\star \star} \\
0,000\end{array}$ & $\begin{array}{l}-, 713^{\star \star} \\
0,000\end{array}$ & $\begin{array}{l}-0,021 \\
0,931\end{array}$ & $\begin{array}{l}0,518^{*} \\
0,019\end{array}$ \\
\hline Recomendação & $\begin{array}{l}\text { Coef. Correlação } \\
\text { Significância }\end{array}$ & $\begin{array}{l}-0,131 \\
0,583\end{array}$ & $\begin{array}{l}0,252 \\
0,283\end{array}$ & $\begin{array}{l}0,066 \\
0,783\end{array}$ & $\begin{array}{l}0,292 \\
0,211\end{array}$ & $\begin{array}{l}-0,190 \\
0,423\end{array}$ & $\begin{array}{l}0,148 \\
0,533\end{array}$ & $\begin{array}{l}-0,263 \\
0,263\end{array}$ & $\begin{array}{l}0,266 \\
0,257\end{array}$ & $\begin{array}{l}0,274 \\
0,243\end{array}$ \\
\hline T. reg. insufic & $\begin{array}{l}\text { Coef. Correlação } \\
\text { Significância }\end{array}$ & $\begin{array}{l}-, 076 \\
0,749\end{array}$ & $\begin{array}{l}-0,013 \\
0,957\end{array}$ & $\begin{array}{l}-0,059 \\
0,803\end{array}$ & $\begin{array}{l}0,455^{*} \\
0,044\end{array}$ & $\begin{array}{l}-0,111 \\
0,642\end{array}$ & $\begin{array}{l}0,199 \\
0,401\end{array}$ & $\begin{array}{l}-0,133 \\
0,577\end{array}$ & $\begin{array}{l}-0,165 \\
0,487\end{array}$ & $\begin{array}{l}0,295 \\
0,297\end{array}$ \\
\hline Solicita reflexão & $\begin{array}{l}\text { Coef. Correlação } \\
\text { Significância }\end{array}$ & $\begin{array}{l}0,220 \\
0,352\end{array}$ & $\begin{array}{l}-0,139 \\
0,559\end{array}$ & $\begin{array}{l}-0,179 \\
0,450\end{array}$ & $\begin{array}{l}0,101 \\
0,673\end{array}$ & $\begin{array}{l}0,060 \\
0,801\end{array}$ & $\begin{array}{l}0,169 \\
0,477\end{array}$ & $\begin{array}{l}0,015 \\
0,950\end{array}$ & $\begin{array}{l}0,042 \\
0,860\end{array}$ & $\begin{array}{l}0,199 \\
0,400\end{array}$ \\
\hline Solicita relato & $\begin{array}{l}\text { Coef. Correlação } \\
\text { Significância }\end{array}$ & $\begin{array}{l}0,338 \\
0,145\end{array}$ & $\begin{array}{l}-0,412 \\
0,071\end{array}$ & $\begin{array}{l}-0,170 \\
0,474\end{array}$ & $\begin{array}{l}-0,102 \\
0,667\end{array}$ & $\begin{array}{l}0,186 \\
0,432\end{array}$ & $\begin{array}{l}-0,063 \\
0,791\end{array}$ & $\begin{array}{l}0,366 \\
0,113\end{array}$ & $\begin{array}{l}-0,178 \\
0,454\end{array}$ & $\begin{array}{l}-0,158 \\
0,506\end{array}$ \\
\hline
\end{tabular}


Tabela 4: Análises de correlação (Teste Sperman's rho), referentes aos dados de duração entre categorias do Terapeuta e Cliente.

\begin{tabular}{|c|c|c|c|c|c|c|c|c|c|c|}
\hline $\begin{array}{l}\text { Categorias do } \\
\text { Terapeuta }\end{array}$ & $\begin{array}{l}\text { Categorias do } \\
\text { Cliente }\end{array}$ & 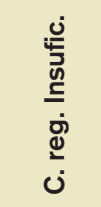 & 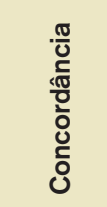 & 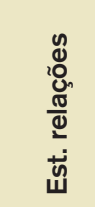 & 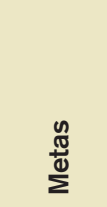 & 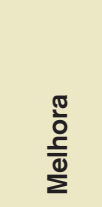 & 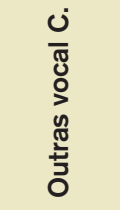 & $\frac{\frac{0}{\pi}}{\frac{\pi}{0}}$ & 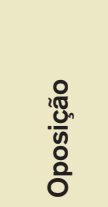 & 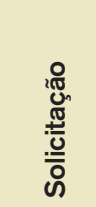 \\
\hline Aprovação & $\begin{array}{l}\text { Coef.Correlação } \\
\text { Significância }\end{array}$ & $\begin{array}{l}-0,180 \\
0,449\end{array}$ & $\begin{array}{l}-0,002 \\
0,994\end{array}$ & $\begin{array}{l}-0,211 \\
0,372\end{array}$ & $\begin{array}{l}0,517^{*} \\
0,019\end{array}$ & $\begin{array}{l}-0,038 \\
0,873\end{array}$ & $\begin{array}{l}-0,159 \\
0,504\end{array}$ & $\begin{array}{l}0,133 \\
0,575\end{array}$ & $\begin{array}{l}-0,020 \\
0,932\end{array}$ & $\begin{array}{l}-0,331 \\
0,154\end{array}$ \\
\hline Empatia & $\begin{array}{l}\text { Coef. Correlação } \\
\text { Significância }\end{array}$ & $\begin{array}{l}-0,060 \\
0,803\end{array}$ & $\begin{array}{l}0,084 \\
0,726\end{array}$ & $\begin{array}{l}-0,372 \\
0,107\end{array}$ & $\begin{array}{l}0,217 \\
0,357\end{array}$ & $\begin{array}{l}-0,406 \\
0,076\end{array}$ & $\begin{array}{l}-0,362 \\
0,117\end{array}$ & $\begin{array}{l}0,280 \\
0,231\end{array}$ & $\begin{array}{l}-0,143 \\
0,548\end{array}$ & $\begin{array}{l}-0,224 \\
0,343\end{array}$ \\
\hline Informações & $\begin{array}{l}\text { Coef. Correlação } \\
\text { Significância }\end{array}$ & $\begin{array}{l}-0,259 \\
0,271\end{array}$ & $\begin{array}{l}0,023 \\
0,924\end{array}$ & $\begin{array}{l}0,352 \\
0,128\end{array}$ & $\begin{array}{l}0,244 \\
0,300\end{array}$ & $\begin{array}{l}0,188 \\
0,428\end{array}$ & $\begin{array}{l}0,499^{*} \\
0,025\end{array}$ & $\begin{array}{l}-0,557 \\
0,011\end{array}$ & $\begin{array}{l}0,336 \\
0,147\end{array}$ & $\begin{array}{l}0,340 \\
0,142\end{array}$ \\
\hline Interpretação & $\begin{array}{l}\text { Coef. Correlação } \\
\text { Significância }\end{array}$ & $\begin{array}{l}0,261 \\
0,267\end{array}$ & $\begin{array}{l}0,141 \\
0,553\end{array}$ & $\begin{array}{l}0,137 \\
0,565\end{array}$ & $\begin{array}{l}0,331 \\
0,154\end{array}$ & $\begin{array}{l}-0,129 \\
0,589\end{array}$ & $\begin{array}{l}0,027 \\
0,909\end{array}$ & $\begin{array}{l}0,049 \\
0,836\end{array}$ & $\begin{array}{l}0,215 \\
0,364\end{array}$ & $\begin{array}{l}-0,153 \\
0,519\end{array}$ \\
\hline Outras vocal T. & $\begin{array}{l}\text { Coef. Correlação } \\
\text { Significância }\end{array}$ & $\begin{array}{l}-0,100 \\
0,674\end{array}$ & $\begin{array}{l}0,048 \\
0,842\end{array}$ & $\begin{array}{l}0,345 \\
0,137\end{array}$ & $\begin{array}{l}-0,117 \\
0,622\end{array}$ & $\begin{array}{l}0,097 \\
0,683\end{array}$ & $\begin{array}{l}0,699^{* *} \\
0,001\end{array}$ & $\begin{array}{l}-0,474 \\
0,035\end{array}$ & $\begin{array}{l}0,032 \\
0,895\end{array}$ & $\begin{array}{l}0,516^{*} \\
0,020\end{array}$ \\
\hline Recomendação & $\begin{array}{l}\text { Coef. Correlação } \\
\text { Significância }\end{array}$ & $\begin{array}{l}-0,131 \\
0,583\end{array}$ & $\begin{array}{l}0,162 \\
0,494\end{array}$ & $\begin{array}{l}0,096 \\
0,687\end{array}$ & $\begin{array}{l}0,221 \\
0,350\end{array}$ & $\begin{array}{l}-0,190 \\
0,423\end{array}$ & $\begin{array}{l}0,117 \\
0,625\end{array}$ & $\begin{array}{l}-0,299 \\
0,201\end{array}$ & $\begin{array}{l}0,372 \\
0,106\end{array}$ & $\begin{array}{l}0,311 \\
0,181\end{array}$ \\
\hline T. reg. insufic & $\begin{array}{l}\text { Coef. Correlação } \\
\text { Significância }\end{array}$ & $\begin{array}{l}-0,076 \\
0,749\end{array}$ & $\begin{array}{l}-0,231 \\
0,328\end{array}$ & $\begin{array}{l}0,033 \\
0,889\end{array}$ & $\begin{array}{l}0,448^{*} \\
0,047\end{array}$ & $\begin{array}{l}-0,111 \\
0,642\end{array}$ & $\begin{array}{l}0,027 \\
0,910\end{array}$ & $\begin{array}{l}-0,024 \\
0,921\end{array}$ & $\begin{array}{l}-0,139 \\
0,558\end{array}$ & $\begin{array}{l}0,045 \\
0,850\end{array}$ \\
\hline $\begin{array}{l}\text { Solicita refle- } \\
\text { xão }\end{array}$ & $\begin{array}{l}\text { Coef. Correlação } \\
\text { Significância }\end{array}$ & $\begin{array}{l}-0,020 \\
0,933\end{array}$ & $\begin{array}{l}-0,206 \\
0,385\end{array}$ & $\begin{array}{l}-0,142 \\
0,551\end{array}$ & $\begin{array}{l}0,361 \\
0,117\end{array}$ & $\begin{array}{l}-0,062 \\
0,796\end{array}$ & $\begin{array}{l}0,146 \\
0,538\end{array}$ & $\begin{array}{l}-0,097 \\
0,683\end{array}$ & $\begin{array}{l}0,175 \\
0,461\end{array}$ & $\begin{array}{l}0,177 \\
0,457\end{array}$ \\
\hline Solicita relato & $\begin{array}{l}\text { Coef. Correlação } \\
\text { Significância }\end{array}$ & $\begin{array}{l}0,259 \\
0,271\end{array}$ & $\begin{array}{l}-0,262 \\
0,264\end{array}$ & $\begin{array}{l}-0,179 \\
0,451\end{array}$ & $\begin{array}{l}-0,352 \\
0,128\end{array}$ & $\begin{array}{l}0,118 \\
0,621\end{array}$ & $\begin{array}{l}-0,241 \\
0,305\end{array}$ & $\begin{array}{l}0,336 \\
0,147\end{array}$ & $\begin{array}{l}-0,201 \\
0,396\end{array}$ & $\begin{array}{l}-0,210 \\
0,373\end{array}$ \\
\hline
\end{tabular}

\section{Discussão}

\section{Comportamentos do terapeuta}

A categoria de Facilitação foi a mais frequente emitida pelos terapeutas. Este resultado corrobora com os resultados encontrados em outros estudos sobre a interação terapêutica, tanto com sessões iniciais de terapeuta-estagiário (Peron \& Lubi 2011), sessões iniciais de terapeutas experientes (Fernandes, 2012) e também todas as sessões do processo terapêutico (Garcia, 2014).

Peron e Lubi (2011) conduziram estudo similar a este, com sessões iniciais de terapeutas em formação. Contudo, no estudo de Peron e Lubi (2011), foram apenas seis sessões de dois terapeutas, e a análise se limitou aos dados de frequência. Este trabalho, na mesma linha do estudo citado, é um avanço na pesquisa de processo em sessões de terapia comportamental, pois apresenta número maior de participantes, e apresenta também dados de duração das categorias.

A categoria Facilitação não apresenta duração, uma vez que trata-se do tipo evento, isto é, não apresenta continuidade, apenas é contabilizada durante a fala do cliente, em termos de frequência. Assim, a categoria Solicitação de relato, segunda maior em frequência, foi a categoria com maior duração nas sessões, assim como nos estudos de Peron e Lubi (2011) e Garcia (2014). Uma hipótese da alta ocorrência/duração desta categoria pode ser justificada pelo caráter da sessão, ou seja, as sessões iniciais de atendimento são marcadas pela coleta de dados e informações pelo terapeuta, como apontado por Silvares e Gongora (1998). 
O comportamento do terapeuta de Recomendação aparece poucas vezes nas sessões analisadas. Pode-se sugerir que exista uma relação entre a baixa frequência deste comportamento com a pouca experiência dos terapeutas (ainda estagiários). Assim, juntamente coma pouca habilidade do terapeuta em emitir este comportamento pode ocorrer insegurança neste momento inicial do processo terapêutico. Peron e Lubi (2011) afirmam que quanto maior a experiência do terapeuta nas intervenções, mais segurança o profissional tem em utilizá-las. O mesmo se aplica para a categoria de Solicitação de reflexão, que aparece com baixa frequência nas sessões.

No que se diz respeito à categoria Reprovação, pode-se dizer que os terapeutas, com objetivo de estabelecer um bom vínculo com seus clientes, não apresentaram tais comportamentos (Zamignani \& Andery, 2005), ou seja, não se comportaram como uma audiência punitiva para os clientes, não emitindo comportamentos como o de Reprovação. No caso da audiência não-punitiva, o terapeuta ouve o relato do cliente sem nenhum tipo de crítica ou julgamento (Skinner, 1953/1993), assim, o terapeuta evita o controle aversivo durante a sessão. O controle aversivo do terapeuta pode dificultar a mudança terapêutica ou prejudicar as relações ao provocar a emissão de comportamentos de fuga e esquiva, subprodutos indesejáveis do controle coercitivo no contexto terapêutico (Alves \& IsidroMarinho, 2010), sobretudo em sessões iniciais, onde o vínculo terapeuta-cliente está em formação (Peron \& Lubi, 2011).

Para Zamignani (2007), comportamentos do terapeuta como a Empatia e a Facilitação, estão relacionados com o acolhimento do cliente e de sua queixa, ou seja, são comportamentos que apontam o terapeuta como sendo uma audiência não punitiva. Nas sessões analisadas, nota-se uma oscilação na frequência e duração da categoria Empatia. No estudo de Garcia (2014), com uma terapeuta experiente (três anos de formação) a categoria empatia oscilou entre 4 e $5 \%$ em termos de frequência, e entre 5 e $8 \%$ em relação a duração. Neste trabalho, observamos que essa média foi semelhante, ficando com 5,2\% em termos de frequência e com $12 \%$ em termos de duração, variando de uma díade terapêutica para outra. A oscilação observada consiste em haver ses- sões com frequência/duração muito baixa, pouco mais de $1 \%$ e outras com taxas elevada na faixa dos $14 \%$, o que pode ser justificado se considerarmos que são estagiários e estão iniciando a prática na clínica, embora em todas as sessões o comportamento Empatia foi emitido, há a possibilidade de se estabilizar de frequência em sessões futuras.

Banaco (1997) afirma que as habilidades do terapeuta de acolher e compreender também estão relacionados com a emissão de algum tipo de resposta de Interpretação ou Informação por parte do terapeuta já nas sessões iniciais. Meyer (2009) aponta em sua tese que o uso de regras ou o controle por consequências imediatas na relação terapêutica, mostrou que a categoria Interpretação seria uma forma de apresentar um controle por regras, uma vez que o terapeuta fornece a análise funcional para o cliente. Entretanto, Peron e Lubi (2011), afirmam que o comportamento verbal vocal de Interpretação do terapeuta engloba a análise de contingências e que o profissional no início do processo possui dados insuficientes sobre o cliente e a historia de vida deste, podendo, portanto, justificar a baixa frequência deste comportamento nas sessões iniciais analisadas.

A categoria Informação geralmente está associada a intervenções "psicoeducacionais" e ao contrato terapêutico (Zamignani, 2007). Nas análises das sessões nota-se frequência em torno de $5 \%$ e duração próxima aos $17 \%$. Esses valores são superiores ao encontrado no estudo de sessões iniciais com terapeutas experientes (Fernandes, 2012) que ficou em 1,09\% de frequência e inferior ao encontrado no estudo de Garcia (2014) que observou entre 6 e $9 \%$ de frequência e 34\% (duração) nas três primeiras sessões. Meyer (2009) afirma que os terapeutas informam muito nas primeiras sessões e essa porcentagem vai caindo ao longo do tempo de terapia, dado que foi ratificado no estudo de Garcia (2014). A duração desta categoria, sendo a segunda mais expressiva após Solicita Relato, corrobora o que foi apontado na literatura.

Em relação à categoria Aprovação, Meyer (2009), afirma que consequenciar diferencialmente por meio de Aprovação força o cliente a ter uma participação mais ativa no processo, fazendo com que o cliente elabore a sua própria análise funcional. Em outro estudo com terapeuta experiente 
(Garcia, 2014), a categoria Aprovação apresentou médias superiores em relação a este estudos, com taxa entre 4 e $7 \%$ de frequência e entre 8 e $14 \%$ de duração. Entretanto, como citado anteriormente, a baixa frequência/duração deste comportamento (inferior a 1\%), pode ser justificado pela pouca experiência profissional na área clínica dos estagiários, podendo aumentar de frequência nas sessões seguintes.

\section{Comportamentos do cliente}

O comportamento do cliente na sessão é uma amostra de padrões de interação que ele estabelece em seu ambiente social e que, ao interagir com o terapeuta, podem ser desenvolvidos novos padrões de interação (Zamignani, 2007). Nesse entendimento, a análise dos comportamentos do cliente é uma possibilidade de análise do processo terapêutico, que pode contribuir como mecanismo de avaliação da terapia.

A categoria mais frequente para o conjunto de clientes, como exposto na seção de resultados, foi a categoria comportamental de Relato. Essa categoria também foi a mais frequente em outros estudos (Garcia, 2014; Peron \& Lubi, 2011; Rossi, 2012), entretanto não com a mesma expressividade (tanto em frequência quanto em duração) quanto a identificada aqui. Uma hipótese para esse elevado índice, talvez seja o fato das sessões aqui analisadas serem de entrevista inicial, e portanto, de coleta de informações e relato (conhecimento) do caso.

Zamignani (2007) aponta em sua tese que a alta taxa de frequência do comportamento de Relato dos clientes é atribuída ao início do processo terapêutico e pela maioria dos clientes estarem sob controle dos próprios questionamentos feitos pelo terapeuta, ou seja, o terapeuta nesse primeiro momento visa coletar dados referentes ao cliente e a sua queixa, para futuras intervenções. Com isso, pode-se dizer que a alta taxa de emissão da categoria Relato do cliente está diretamente relacionada com a frequência dos comportamentos de Facilitação e Solicitação de Relato, ambos emitidos pelo terapeuta.

A segunda categoria comportamental do grupo de clientes, em termos de frequência, foi Concordância. Peron e Lubi (2011) afirmam que o comportamento do cliente em relatar concordân- cia ou confiança, categorizadas no SiMCCIT como Concordância, são próprias da interação entre duas pessoas, e numa sessão de terapia contempla o resumo e a complementação por parte do cliente das falas do terapeuta. E por essa natureza, de sumarização/concordância, observamos na Tabela 2, que Concordância não se destacou em relação ao tempo, na mesma expressividade com que foi em frequência (Tabela 1).

Outras categorias de relevância que foram identificadas nas análises foram Solicitação, Melhora, Metas e Oposição. Em relação à primeira, Solicitação, observa-se uma frequência ligeiramente superior às outras, mas não muito expressiva, se comparada a Relato e Concordância. Solicitação é categorizada quando o cliente solicita informações, opiniões e/ou asseguramento. Como as sessões analisadas eram as primeiras sessões do processo terapêutico, é de se esperar que esta categoria se evidencie mais que as outras (Melhoras e Metas), pois o cliente estará se habituando à terapia, tirando dúvidas, se assegurando de como ocorrerá a terapia.

Assim, devido a natureza das sessões aqui analisadas, é de se esperar que os clientes relatem mais os eventos e fatos que estão envolvidos com sua queixa, do que planejar o que fazer futuramente ou de se opor aos comportamentos do terapeuta, que em grande maioria, estão relacionados com Solicitação de relato.

\section{A díade terapêutica e suas correlações}

Nas interações terapêuticas analisadas neste estudo, podem-se observar algumas correlações estabelecidas entre os comportamentos dos terapeutas e clientes conforme apontado nas Tabelas 3 e 4 . Considerando que este trabalho teve como foco as sessões inicias de atendimento e os resultados apontaram alta frequência de poucas categorias comportamentais (Facilitação e Solicitação de Relato - Terapeuta e Relato - Cliente) e baixa frequência das outras categorias, as análises de correlação detectaram poucas correlações estabelecidas, sendo seis com categorias significativas ${ }^{1}$

1 As descrições aqui apresentadas desconsideraram as categorias residuais que o SiMCCIT detecta, que são Outras Vocal e Registro Insuficiente (Terapeuta e Cliente), por entendermos que tais categorias não são significativas para a análise da 
para os dados de frequência e apenas uma para os dados de duração.

Houve correlação negativa entre a categoria Empatia (Terapeuta) com Melhora e com Solicitação (Cliente). A literatura de interação terapêutica não apresenta consenso em relação a esses comportamentos. O estudo de Elliot et al. (2011) apontou que comportamentos que demonstram apoio e compreensão do terapeuta (que se assemelham a definição da categoria Empatia do Terapeuta no SiMCCIT) podem aumentar o engajamento e exposição dos clientes (que podemos associar com as categorias de Melhora e Solicitação do Cliente no SiMCCIT). Por outro lado, o estudo de Harwood (2003) aponta que a empatia pode desfavorecer relatos de melhora dos clientes e pode contribuir para o pessimismo ou para o reforço inadvertidamente dos relatos de queixas através da supervalorização das mesmas. A correlação negativa apontada neste estudo pode ser entendida se considerarmos a natureza das sessões aqui analisadas, sessões iniciais de terapia e o fato de serem terapeutas iniciantes.

A categoria Informações do Terapeuta foi correlacionada positivamente com a categoria Relações e Solicitação, ambas do Cliente. Sobre Informações com Relações, dados semelhantes foram os resultados encontrados por Silveira et al. (2014) com sessões diversas do processo terapêutico. O Terapeuta fornece algumas informações para o cliente e por meio delas o Cliente é capaz de estabelecer relações entre os eventos. Sabe-se que estabelecer relação entre os eventos proporciona o autoconhecimento, que por sua vez, funciona como um pré-requisito para o autocontrole e outras mudanças comportamentais importantes (Skinner, 1993/1953). Este dado sugere que apesar de serem sessões iniciais do processo terapêutico, e assim, não ser objetivo central dessas sessões promoverem tais reflexões/mudanças, não há como separar no processo terapêutico a simples coleta de dados com a intervenção em si.

A correlação positiva entre Informações e Solicitação, também foi apontada no estudo de Garcia (2014). Nesta situação, pode-se observar que o Cliente ao solicitar algo para o Terapeuta,

interação terapêutica e sua categorização ocorre por recurso didático, ou seja, a necessidade de se classificar todas as verbalizações durante as sessões. trará como consequência informações fornecidas pelo Terapeuta. Ou seja, quanto mais informações o Terapeuta passava ao Cliente, mais ele indagava e questionava sobre essas informações, sendo apontados por Castonguay e Beutler (2006) como uma prática que auxilia no processo terapêutico e favorece a adesão ao tratamento, uma vez que o cliente se torna ativo (participativo) no processo.

Por sua vez, a categoria Informações correlacionou-se negativamente com a categoria Relato. Pode-se hipotetizar que ao fornecer uma informação, o Terapeuta pode inibir o comportamento do Cliente de relatar alguns eventos, visto que o terapeuta já fornece a informação sem o Cliente, necessariamente, fazer o relato. Essa correlação não havia sido detectada na literatura da área.

Observa-se também uma correlação positiva entre a categoria Interpretação do Terapeuta com a categoria Concordância do Cliente, correlação essa já identificada em outros estudos (Garcia, 2014; Orlinsky, Grawe, \& Parks, 1994; Patterson \& Chamberlain, 1994). Esse dado sugere duas hipóteses: a primeira é de que tais interpretações serviam para assegurar ao estagiário que o que ele estava compreendendo era o que realmente o cliente estava dizendo, embasando assim a sua formulação do caso, e a outra possibilidade, é de que já ocorria uma intervenção por parte do terapeuta, que apesar de ainda serem estagiários, apresentavam o comportamento de interpretação dos conteúdos verbalizados pelos clientes. Em ambas as possibilidades, o comportamento do estagiário ocasionou concordância por parte dos clientes.

Para os dados de duração, a única correlação com categorias funcionais (Tabela 4), foi a de Aprovação (Terapeuta) com Metas (Cliente). Interessante observar que a categoria de Aprovação, tal como apontado por Zamignani (2007), pressupõe o terapeuta como alguém que pode selecionar e fortalecer aspectos do comportamento do cliente que seriam mais ou menos apropriados. Assim, quando o Terapeuta identifica estes comportamentos, e faz essa seleção, o Cliente apresenta comportamento de comprometimento com o processo e formula Metas. No estudo de Peron e Lubi (2011), que também trabalhou com sessões iniciais, não foram identificados tais comportamentos. Analisando as Tabelas 1 e 2, observamos que algumas díades 
também não apresentaram comportamentos de Aprovação e de Metas, mas aquelas que apresentaram um deles também apresentou o outro, evidenciando a relação apontada no teste estatístico.

O estudo da interação terapêutica mediante a análise por um sistema de categorias comportamentais permitiu identificar que o terapeuta direciona a intervenção para os objetivos propostos, assim como apontado na literatura (Calero-Elvira et al., 2013; Ruiz-Sancho et al., 2013). Neste caso, como o objetivo era a coleta de dados para a elaboração da intervenção, houve maior expressividade (em termos de frequência e duração) de categorias comportamentais do terapeuta que favorecessem esse objetivo, sendo elas de Solicitação de Relato e Facilitação. Entretanto, o aprofundamento do estudo da interação terapêutica mediante a análise de correlações entre as variáveis da interação (comportamentos do terapeuta e cliente), permitiu verificar que as sessões iniciais, também se configuram de alguma forma em intervenção, como pode-se supor diante de algumas correlações, como Informações com Relações, Interpretação com Concordância e Aprovação com Metas.

\section{Considerações finais}

A partir da pesquisa realizada, observa-se que as contribuições trazidas são capazes de identificar quais os comportamentos de terapeutas e de clientes que se demonstraram mais frequentes e com maior duração durante sessões de terapias iniciais. Também foi possível identificar (apesar de terem sido poucas), as correlações entre categorias comportamentais do Terapeuta com o Cliente.

Dando sequencia a este estudo, novas pesquisas podem contribuir na expansão do conhecimento no estudo da interação terapêutica em sessões iniciais. Novas pesquisas com essas características permitiriam verificar se as baixas taxas de comportamentos típicos de intervenção do Terapeuta (Recomendação. Interpretação, Solicitar Reflexão) aqui encontrados, são realmente fruto da natureza da sessão (coleta de informações) ou se a variável pouca experiência dos terapeutas é responsável pelos resultados.

\section{Referências}

Alves, N. N. F., \& Isidro-Marinho, G. (2010). Relação Terapêutica sob a perspectiva analítico comportamental. Em A. K. C. R de Farias (Orgs.), Análise Comportamental Clínica: aspectos teóricos e estudos de caso (pp. 66-94). Porto Alegre, RS: Artmed.

Banaco, R. A. (1997). Tendências neo-behavioristas na terapia comportamental: Uma análise sobre a relação terapêutica. Em P. F. Castro (coord.), Anais do I Encontro sobre Psicologia Clínica da Universidade Mackenzie, 36-43. São Paulo, SP.

Brito, I. G. S., Oliveira, J. A., \& Sousa, L. F. D. (2003). A relação terapêutica evidenciada através do método da observação direta. Revista Brasileira de Terapia Comportamental e Cognitiva, 2, 139-149.

Barbosa, J. I. C., \& Tourinho, E. Z. (2009). Verbalizações de terapeuta e cliente e estabelecimento de relações na evolução de uma terapia analítico-comportamental. Revista Brasileira de Terapia Comportamental e Cognitiva, 11, 10-31. Calero-Elvira, A., Froján-Parga, M. X., RuizSancho, E. M., \& Alpañés-Freitag, M. (2013). Descriptive Study of the Socratic Method: Evidence for Verbal Shaping. Behavior Therapy, 44, 625-638.

Castonguay, L. G., \& Beutler, L. E. (2006). Common and unique principles of therapeutic change: What do we know and what do we need to know. Em L. G. Castonguay \& L. E. Beutler (Eds.), Principles of therapeutic change that work (pp. 353-369). New York, NY: Oxford University Press.

Cozby, P. C. (2003). Métodos de pesquisa em ciências do comportamento. São Paulo, SP: Atlas.

Donadone, J. C. (2009). Análise de contingências de orientações e auto-orientações em intervenções clínicas comportamentais (Tese de Doutorado). Instituto de Psicologia, Universidade de São Paulo, São Paulo.

Elliot, R., Bohart, A. C., Watson, J. C., \& Greenberg, L. S. (2011). Empathy. Psychotherapy, 48, 46-49.

Fernandes, F. A. D. (2012). Relação terapêutica: uma análise dos comportamentos de terapeuta e cliente em sessões iniciais de terapia (Dissertação de Mestrado). Instituto de Psicologia, Universidade de São Paulo, São Paulo. 
Garcia, M. R. (2001). Uma tentativa de identificação de respostas de esquiva e da utilização do procedimento de bloqueio de esquiva através da análise de uma relação terapêutica (Dissertação de Mestrado). Pontifícia Universidade Católica, São Paulo.

Garcia, V. A. (2014). Análise da interação terapêutica em intervenções com universitários com transtorno de ansiedade social. (Dissertação de Mestrado). Universidade Estadual Paulista "Júlio de Mesquita Filho", Bauru.

Harwood, M. D. (2003). Effect of therapist process variables on treatment outcome forparent-child interaction therapy (PCIT) (Dissertação de Mestrado). University of Florida, Flórida.

Kanamota, P. F. C., Kanamota, J. S. V., \& BolsoniSilva, A. T. (2014). Um estudo de intervenção psicoterapêutica com mãe de adolescente com problema de comportamento. Em D. Zamignani, \& S. B. Meyer (Org.). A pesquisa de processo em psicoterapia: estudos a partir dos instrumentos SIMCCIT (pp. 183-196). São Paulo, SP: Núcleo Paradigma.

Meyer, S. (2009). Análise de 'Solicitação de Informação' e 'Recomendação' em banco de dados de terapias comportamentais (Tese de Livre-Docência). Instituto de Psicologia, Universidade de São Paulo, São Paulo.

Orlinsky, D. E., Grawe, K., \& Parks, B. K. (1994). Process and outcome in psychotherapy. Em A. E. Bergin, \& Garfield, S. L. (Eds.). Handbook of psychotherapy and behavior change (pp. 270376). New York, NY: Wiley.

Patterson, G. R., \& Chamberlain, P. (1994). A functional analysis of resistance during parent training therapy. Clinical Psychology: Science and Practice, 1, 53-70.

Peron, F., \& Lubi, A. P. L. (2011). Instâncias da relação terapêutica medidas a partir de um instrumento de categorização. Acta Comportalia, 20, 109-123.

Rosenfarb, I. S. (1992). A behavior analytic interpretation of the therapeutic relationship. The Psychological Record, 42, 341-354.

Rossi, P. R. (2012). Categorização da quarta sessão de psicoterapias bem e mal sucedidas (Dissertação de Mestrado). Instituto de Psicologia, Universidade de São Paulo, São Paulo.
Ruiz-Sancho, E. M., Frojan-Parga, M. X., \& CaleroElvira, A. (2013). Functional Analysis of the Verbal Interaction Between Psychologist and Client During the Therapeutic Process. Behavior Modification, 37, 516-542.

Sadi, H. M. (2011). Análise dos comportamentos de terapeuta e cliente em um caso de Transtorno de Personalidade Boderline (Tese de Doutorado). Instituto de Psicologia, Universidade de São Paulo, São Paulo.

Silvares, E. F. M., \& Gongora, M. A. N. (1998). Psicologia clínica comportamental: A inserção da entrevista com adultos e crianças. São Paulo, SP: Edicon.

Silveira. F. F., Bolsoni-Silva, A. T., \& Meyer, S. B. (2010). Therapist's directive and nondirective behavior: Analysis of their effects in a parent training group. International Journal of Behavioral Consultation and Therapy, 6, 124-133.

Silveira, F. F., Meyer, S. B., \& Bolsoni-Silva, A. T. (2014). Intervenção analítico-comportamental de grupo: descrevendo categorias de comportamento dos participantes. Em D. Zamignani, \& S. B. Meyer (Org.). A pesquisa de processo em psicoterapia: estudos a partir dos instrumentos SIMCCIT (pp. 39-56). São Paulo, SP: Núcleo Paradigma.

Skinner, B. F. (1993). Ciência e comportamento humano. São Paulo: Martins Fontes. (Trabalho original publicado em 1953).

The Observer XT. (2005). Noldus Information Technology. Versão 7.0

Vermes, J. S. (2000). Uma avaliação dos comportamentos do terapeuta comportamental: subsídios para a formação. Pesquisa de iniciação cientifica. Faculdade de Psicologia, Pontifícia Universidade Católica de São Paulo, São Paulo.

Yano, Y. (2003). Tratamento padronizado e individualizado no transtorno do pânico (Tese de Doutorado). Instituto de Psicologia, Universidade de São Paulo, São Paulo.

Zamignani, D. R. (2007). O desenvolvimento de um sistema multidimensional para a categorização de comportamentos na interação terapêutica (Tese de Doutorado). Instituto de Psicologia, Universidade de São Paulo, São Paulo.

Zamignani, D. R., \& Andery, M. A. P. A. (2005). Interação entre Terapeutas Comportamentais 
e Clientes Diagnosticados com Transtorno Obsessivo-Compulsivo. Psicologia: Teoria e Pesquisa, 21, 109-119.

Zamignani, D. R., \& Meyer, S. B. (2011). Comportamentos verbais do terapeuta no sistema multidimensional para a categorização de comportamentos na interação terapêutica. Perspectivas em Análise do Comportamento, 2, 25-45.

Zamignani, D. R. \& Meyer, S. B. (Orgs.) (2014a). A pesquisa de processo em psicoterapia: o desenvolvimento do SiMCCIT. São Paulo, SP: Núcleo Paradigma.

Zamignani, D. R. \& Meyer, S. B. (Orgs.) (2014b). A pesquisa de processo em psicoterapia: estudos a partir do instrumento SiMCCIT . São Paulo, SP: Núcleo Paradigma. 